\title{
Intramolecular Alkene Carboamination Reactions for the Synthesis of Enantiomerically Enriched Tropane Derivatives
}

\author{
Danielle M. Schultz and John P. Wolfe* \\ Department of Chemistry, University of Michigan, 930 N. University Avenue, Ann Arbor, Michigan, \\ 48109-1055
}

\section{Abstract}
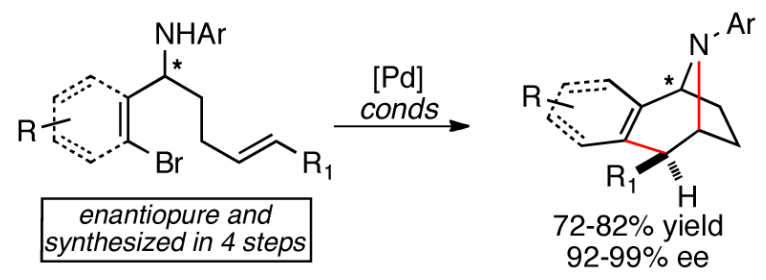

The synthesis of tropane derivatives via intramolecular Pd-catalyzed alkene difunctionalization reactions is described. Enantiopure $N$-aryl- $\gamma$-aminoalkenes bearing an aryl or alkenyl halide adjacent to the amino group were converted to benzo- or cycloalkenyl-fused tropane products in good yield and with no loss of enantiopurity.

The azabicyclic framework is widespread in both natural products and pharmaceutical targets that have a range of central nervous system (CNS) activities including anticholinergic, sedatory, and cognitive. ${ }^{1}$ Benzo-fused tropanes are an interesting and important subclass of azabicycloalkanes. These ring systems are displayed in numerous drug leads and pharmaceuticals including $\mathbf{1}$, which has been studied for the treatment of Type 2 diabetes, ${ }^{2}$ and $\mathbf{2}$, which is an anti-tumor drug candidate. ${ }^{3}$ MK-801 (dizocilipine), a related heterocycle bearing two fused aryl rings, has exhibited anticonvulsant activity, ${ }^{4 a}$ and has also been used in animal models of schizophrenia. ${ }^{4 b}$

The medicinal relevance of azabicycloalkanes has stimulated considerable interest among synthetic chemists, and a great number of methods have been developed for the construction of saturated frameworks. ${ }^{5,6,7}$ In contrast, only a handful of routes have previously been developed for the synthesis of benzo-fused tropane scaffolds. ${ }^{8,9,10,11,12}$ We envisioned that an intramolecular Pd-catalyzed carboamination reaction ${ }^{13,14}$ of a $\gamma$-aminoalkene substrate such as $\mathbf{4}$, which contains a 2-bromoaryl (or 2-bromoalkenyl) group adjacent to the amino moiety, could provide a complementary approach to the benzo-tropane framework $\mathbf{3}$ (Scheme 1). This transformation would generate two bonds and 1-2 stereocenters (at C8 and C9) in a controlled fashion, and the requisite substrates could be prepared in enantiopure form via addition of unsaturated Grignard reagents $\mathbf{6}$ to readily available chiral imines $\mathbf{5}$.

\footnotetext{
“jpwolfe@umich.edu .
}

Supporting Information Available.

Experimental procedures, characterization data for all new compounds, descriptions of stereochemical assignments with supporting structural data, and copies of ${ }^{1} \mathrm{H}$ and ${ }^{13} \mathrm{C}$ NMR spectra for all new compounds reported in the text. This material is available free of charge via the Internet at http://pubs.acs.org. 
The enantioenriched substrates $\mathbf{4}$ required for the strategy outlined above were synthesized in 4 steps from readily accessible $o$-bromobenzaldehydes or $\beta$-bromo- $\alpha, \beta$-unsaturated aldehydes (Scheme 2). Specifically, condensation of an appropriate bromoaldehyde with $\left(R_{S}\right)$-(+)-tert-butanesulfinamide ${ }^{15}$ afforded aldimine 7 as a single enantiomer. Subsequent 1,2-addition of a homoallylic Grignard reagent to 7 afforded $N$-tert-butanesulfinyl amines 8. ${ }^{16}$ The Grignard addition reactions typically proceeded with 4-13:1 dr, but after flash chromatography the desired amine products were obtained with a high degree of stereochemical purity in moderate to good yield (51-76\%). In the few instances when the diastereoselectivity of the Grignard addition to the aldimine was poor (2-3:1), lower yields (38-46\%) of amine products were obtained after separation of the stereoisomers. Acidmediated cleavage of the chiral auxiliary to give primary amines $\mathbf{9}$, followed by a Pd/ Xantphos-catalyzed $N$-arylation ${ }^{17}$ with bromobenzene, afforded desired $N$-phenyl- $\gamma$ aminoalkene substrates $\mathbf{4 a - h}$ in good yield. Although these conditions usually provided good chemoselectivity for the desired $N$-arylation, in a few instances competing 2-benzyl pyrrolidine formation occurred, which led to modest yields.

Our prior studies on Pd-catalyzed carboamination reactions that yield substituted pyrrolidines suggested the conversion of $\mathbf{4}$ to $\mathbf{3}$ was likely to occur via a key intramolecular aminopalladation of an intermediate Pd(aryl)(amido) complex such as $\mathbf{1 0}$ (Scheme 3). ${ }^{13,14}$ The general feasibility of this process was supported by prior studies in our lab, which illustrated that intramolecular carboaminations of substrates such as $\mathbf{1 1}$ effectively generated pyrrolidines bearing attached carbocyclic rings (e.g., 13). ${ }^{18}$ This latter transformation is believed to proceed via intramolecular (transannular) insertion of the alkene into macrocyclic Pd(aryl)(amido) complex 12, which bears a single phosphine ligand. ${ }^{19}$ As such, we elected to examine catalysts supported by monodentate phosphines in our initial optimization experiments.

The optimization of conditions for the tropane-forming reactions was explored using substrate 4a (Table 1). Our optimization studies focused on phosphine ligand structure, using otherwise standard conditions known to give satisfactory results in most carboamination reactions $\left(\mathrm{NaO}^{t} \mathrm{Bu}\right.$, toluene, $\left.90-110^{\circ} \mathrm{C}\right)$. Use of $\mathrm{P}(o \text {-tol })_{3}$ as the ligand led to incomplete conversion of the starting material and only afforded small quantities of the desired tropane product. Improved results were obtained with the bulky electron-rich DavePhos $^{20 a}$ ligand, but the reaction still failed to reach completion. However, use of the slightly smaller electron-rich ligand $\mathrm{PCy}_{3}{ }^{21}$ led to complete consumption of the starting material and provided $\mathbf{1 4}$ in $77 \%$ isolated yield (entry 4). Finally, to probe the hypothesis that the key intermediate bears a single phosphine ligand, the efficacy of the bidentate ligand dppf was examined. As postulated, poor conversion of starting material occurred and only a low yield of $\mathbf{1 4}$ was obtained (entry 5).

With optimized reaction conditions in hand, the scope and limitations of the intramolecular carboamination reactions were explored. Overall these transformations proved to be quite general, and afforded various tropane derivatives in good yields and with no loss of enantiopurity (Table 2). The presence of a methylenedioxy group on the aryl bromide was tolerated (entry 3), and the heteroaryl-fused tropane 17 was generated from pyridine derivative $\mathbf{4 d}$ in good yield. Cyclic alkenyl halides were also viable substrates, as $\mathbf{4 e - f}$ were efficiently transformed to unsaturated tropanes 18-19 (entries 5 and 6 , respectively). Unfortunately, efforts to transform non-cyclic alkenyl halide substrates into tropane products were unsuccessful, as alkene isomerization and substrate decomposition occurred more rapidly than tropane formation.

The method is also amenable to the generation of quaternary stereocenters, as seen in the conversion of 1,1-disubstituted alkene substrates $\mathbf{4 c}$ and $\mathbf{4 f}$ to $\mathbf{1 6}$ and $\mathbf{1 9}$, respectively. The 
stereospecific conversion of $E$ - and $Z$-alkene substrates $4 \mathrm{~g}$ and $4 \mathrm{~h}$ proceeded smoothly to provide disubstituted tropane products 20 and 21. In these latter transformations, use of the slightly smaller ligand $\mathrm{PPh}_{2} \mathrm{Cy}$ provided better results than our standard $\mathrm{Pd} / \mathrm{PCy} y_{3}$ catalyst system. Styrene-derived substrate $\mathbf{4 b}$ smoothly underwent the intramolecular carboamination reaction to yield dibenzotropane $\mathbf{1 5}$ in good yield.

In order to further demonstrate the utility of this method, we sought to prepare MK-801 analog 24 (Scheme 4). This compound has served as a common intermediate en route to MK-801 and derivatives, and also exhibits modest NMDA antagonist activity. ${ }^{4 a, 22}$ The synthesis of $\mathbf{2 4}$ has previously been accomplished via base-mediated transannular hydroamination of an amino alkene. This route afforded ( \pm -24 in three steps from commercially available material. ${ }^{23}$ Although this is an effective approach to the racemate, an analogous route to enantioenriched samples of $\mathbf{2 4}$ has not been developed. ${ }^{24}$

In our synthesis of $\mathbf{2 4}$ we sought to effect the carboamination of a substrate related to diphenylmethylamine derivative $\mathbf{4 b}$, but with a cleavable group on the nitrogen atom in place of the $N$-phenyl substituent. Initial efforts to employ $N$-Boc-protected variants of $\mathbf{4 b}$ were unsuccessful, and led to either low conversion or decomposition of the starting material. As such, an $N$-PMP group was selected as the amine substituent, as this aryl protecting group can be cleaved under oxidizing conditions. The requisite substrate $\mathbf{2 2}$ was prepared in 3 steps and with $37 \%$ overall yield from $o$-chlorobenzaldehyde using the route described above in Scheme $2 .{ }^{25}$ The $\mathrm{Pd}_{2}(\mathrm{dba})_{3} / \mathrm{PCy}_{3} \cdot \mathrm{HBF}_{4}$ catalyst was not sufficiently reactive to promote complete conversion of $\mathbf{2 2}$ to $\mathbf{2 3}$, and a significant amount of unreacted starting material was recovered. However, we were gratified to find that S-Phos, ${ }^{20 \mathrm{~b}}$ an electron-rich ligand recently shown to be effective in intermolecular carboamination reactions between aryl chlorides and $N$-substituted- $\gamma$-amino alkenes, ${ }^{26}$ led to complete substrate conversion. These conditions provided desired tropane $\mathbf{2 3}$ in excellent yield and with no loss of enantiopurity. Treatment of $\mathbf{2 3}$ with $\mathrm{CAN}$ in aqueous acetonitrile at $0{ }^{\circ} \mathrm{C}$ led to clean removal of the PMP group, and provided 24 in $74 \%$ yield.

In conclusion, we have developed a new method for the synthesis of benzo-fused tropanes via an intramolecular Pd-catalyzed alkene carboamination reaction. This method allows for straightforward preparation of $N$-aryl benzotropanes bearing substituents at $\mathrm{C} 8, \mathrm{C} 9$, or on the fused arene ring. In addition, $\mathrm{N}-\mathrm{H}$ tropanes can be accessed through deprotection of $\mathrm{N}$ PMP derivatives. Further studies on the application of this method to the construction of complex tropane alkaloids are currently underway.

\section{Supplementary Material}

Refer to Web version on PubMed Central for supplementary material.

\section{Acknowledgments}

The authors acknowledge the NIH-NIGMS for financial support of this work. Additional funding was provided by GlaxoSmithKline, Amgen, and Eli Lilly. D.M.S. acknowledges the ACS Division of Organic Chemistry for a graduate fellowship and the University of Michigan for a Rackham predoctoral fellowship.

\section{References}

1. Grynkiewicz G, Gadzikowska M. Pharmacological Reports. 2008; 60:439. [PubMed: 18799813]

2. Ammenn J, Paal M, Ruehter G, Schotten T, Stenzel W. PCT Int. Appl. WO 2000078724. 2000

3. Ahmed G, Bohnstedt A, Breslin HJ, Burke J, Curry MA, Diebold JL, Dorsey B, Dugan BJ, Feng D, Gingrich DE, Guo T, Ho K-K, Learn KS, Lisko JG, Liu R-Q, Mesaros EF, Milkiewicz K, Ott GR, 
Parrish J, Theroff JP, Thieu TV, Tripathy R, Underiner TL, Wagner JC, Weinberg L, Wells GJ, You M, Zificsak CA. PCT Int. Appl. WO 2008051547. 2008

4. (a) Thompson WJ, Anderson PS, Britcher SF, Lyle TA, Thies JE, Magill CA, Varga SL, Schwering JE, Lyle PA, Christy ME, Evans BE, Colton CD, Holloway MK, Springer JP, Hirschfield JM, Ball RG, Amato JS, Larsen RD, Wong EHF, Kemp JA, Tricklebank MD, Singh L, Oles R, Priestly T, Marshall GR, Knight AR, Middlemiss DN, Woodruff GN, Iversen LL. J. Med. Chem. 1990; 33:789. [PubMed: 1688947] (b) Rung JP, Carlsson A, Markinhuhta KR, Carlsson ML. Prog. Neuropsychopharmacol. Biol. Psych. 2005; 29:827.

5. For a recent review, see: Pollini GP, Benetti S, De Risi C, Zanirato V. Chem. Rev. 2006; 106:2434. [PubMed: 16771455]

6. For selected recent examples, see: (a) Lin G-J, Zheng X, Huang P-Q. Chem. Commun. 2011; 47:1545. (b) Davis FA, Theddu N, Edupuganti R. Org. Lett. 2010; 12:4118. [PubMed: 20731370] (c) Reddy RP, Davies HML. J. Am. Chem. Soc. 2007; 129:10312. [PubMed: 17685525] and references cited therein. (d) Shing TKM, Wong WF, Ikeno T, Yamada T. Org. Lett. 2007; 9:207. [PubMed: 17217266] (e) Martin SF. Pure Appl. Chem. 2005; 77:1207. (f) Mans DM, Pearson WH. Org. Lett. 2004; 6:3305. [PubMed: 15355038] and references cited therein. (g) Mikami K, Ohmura H. Chem. Commun. 2002:2626.

7. For pioneering studies see: (a) Robinson R. J. Chem. Soc. Trans. 1917; 111:762. (b) Willstätter R, Wolfes O, Mader H. Liebigs Ann. Chem. 1923; 434:111. (c) Schopf C, Lehman G. Liebigs Ann. Chem. 1935; 518:1.

8. For radical cyclization approaches, see: (a) Funabashi K, Ratni H, Kanai M, Shibasaki M. J. Am. Chem. Soc. 2001; 123:10784. [PubMed: 11674030] (b) Ikeda M, Hamada M, El Bialy SAA, Matsui K, Kawakami S, Nakano Y, Bayomi SMM, Sato T. Heterocycles. 2000; 52:571.

9. For approaches involving Diels-Alder reactions, see: (a) Constable KP, Blough BE, Carroll FI. Chem. Commun. 1996:717. (b) Grunewald GL, Sall DJ, Monn JA. J. Med. Chem. 1988; 31:433. [PubMed: 3339613]

10. For [3+2] cycloaddition approaches, see: (a) Xing S, Pan W, Liu C, Ren J, Wang Z. Angew. Chem. Int. Ed. 2010; 49:3215. (b) Grigg R, Somasunderam A, Sridharan V, Keep A. Synlett. 2009:97. (c) Yeom H-S, Lee J-E, Shin S. Angew. Chem. Int. Ed. 2008; 47:7040. (d) Padwa A, Dean DC, Osterhout MH, Precedo L, Semones MA. J. Org. Chem. 1994; 59:5347.

11. For an approach involving Pd-catalyzed allylic alkylation, see: Li Q, Jiang X, Fu C, Ma S. Org. Lett. 2011; 13:466. [PubMed: 21182260]

12. For a hydroamination approach, see: Molander GA, Dowdy ED. J. Org. Chem. 1999; 64:6515. 13. For reviews see: (a) Wolfe JP. Eur. J. Org. Chem. 2007:571. (b) Wolfe JP. Synlett. 2008:2913.

14. (a) Ney JE, Wolfe JP. Angew. Chem., Int. Ed. 2004; 43:3605.(b) Bertrand MB, Neukom JD, Wolfe JP. J. Org. Chem. 2008; 73:8851. [PubMed: 18942792] (c) Lemen GS, Wolfe JP. Org. Lett. 2010; 12:2322. [PubMed: 20405853]

15. Robak MT, Herbage MA, Ellman JA. Chem. Rev. 2010; 110:3600. [PubMed: 20420386]

16. Efforts to prepare substrates bearing quaternary stereocenters adjacent to the amino group were unsuccessful due to the low reactivity of $N$-sulfinyl ketimines towards organometallic nucleophiles.

17. (a) Yang BH, Buchwald SL. Org. Lett. 1999; 1:35. [PubMed: 10822529] (b) Janey, JM. Name Reactions for Functional Group Transformations. Li, JJ., editor. John Wiley \& Sons; Hoboken, NJ: 2007. p. 566-611.

18. Nakhla JS, Kampf JW, Wolfe JP. J. Am. Chem. Soc. 2006; 128:2893. [PubMed: 16506768]

19. Recent mechanistic studies also suggest that alkene aminopalladation occurs most rapidly from palladium complexes bearing one phosphine ligand. See: (a) Neukom JD, Perch NS, Wolfe JP. Organometallics. 2011; 30:1269. (b) Neukom JD, Perch NS, Wolfe JP. J. Am. Chem. Soc. 2010; 132:6276. [PubMed: 20397666] (c) Hanley PS, Markovic D, Hartwig JF. J. Am. Chem. Soc. 2010; 132:6302. [PubMed: 20408534]

20. Ligand definitions: (a) DavePhos = 2-dicyclohexylphosphino-2'-( $N, N$-dimethylamino)-biphenyl. (b) S-Phos = 2-Dicyclohexylphosphino- 2',6'-dimethoxybiphenyl.

21. This ligand was employed as the air-stable tetrafluoroborate salt, which was obtained from commercial sources. 
22. (a) Monn JA, Rice KC. Tetrahedron Lett. 1989; 30:911.(b) Monn JA, Thurkauf A, Mattson MV, Jacobson AE, Rice KC. J. Med. Chem. 1990; 33:1069. [PubMed: 2155320]

23. Lamanec TR, Bender DR, DeMarco AM, Karady S, Reamer RA, Weinstock LM. J. Org. Chem. 1988; 53:1768.

24. Enantiopure samples of $\mathbf{2 4}$ have previously been generated via resolution of the racemate. See reference $4 \mathrm{a}$.

25. Initial efforts to use 2-bromobenzaldehyde for the construction of the aryl bromide analog of 22 were unsuccessful, as $\mathrm{N}$-arylation of the primary diarylmethylamine with 4-bromoanisole suffered from competing intramolecular Heck reaction of the bromoalkene.

26. Rosen BR, Ney JE, Wolfe JP. J. Org. Chem. 2010; 75:2756. [PubMed: 20297834] 

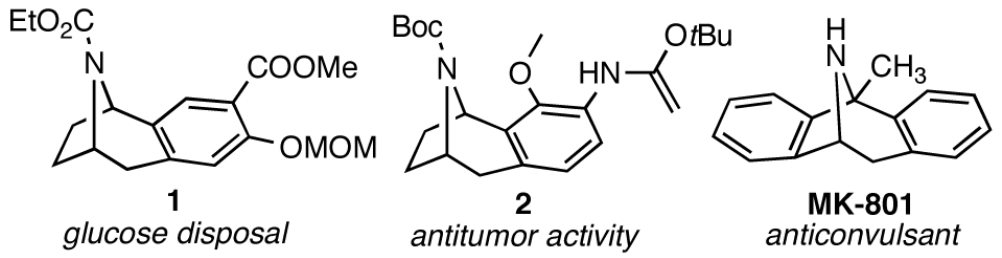

Figure 1.

Biologically Active Benzo-Fused Tropanes 


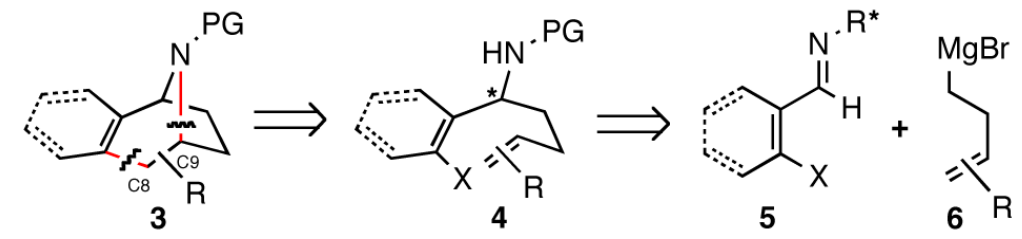

Scheme 1.

Intramolecular Carboamination Strategy for the Synthesis of Benzo-Fused Tropane Derivatives 

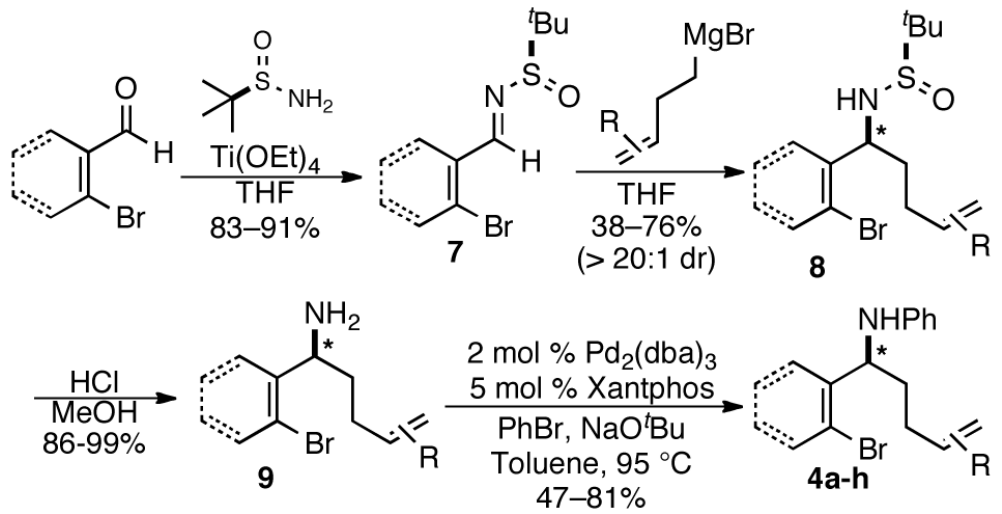

Scheme 2.

Synthesis of Tropane Substrates ${ }^{\mathrm{a}}$ 


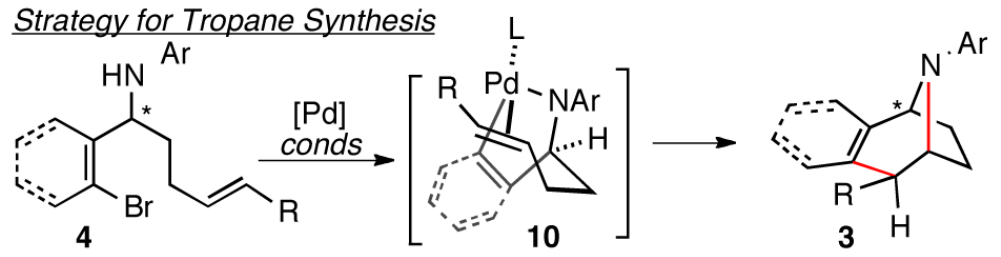

Prior Work: Intramolecular Carboamination

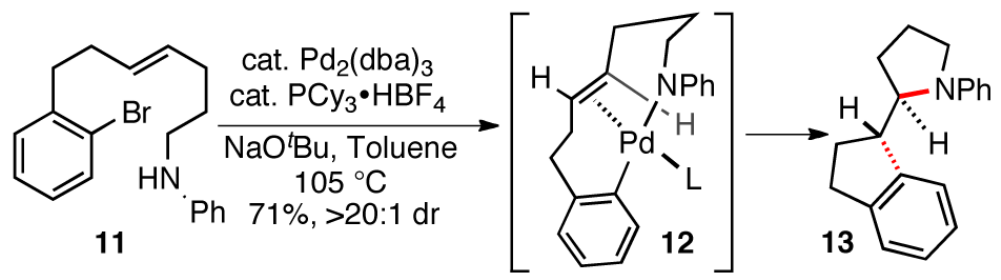

Scheme 3.

Intramolecular Carboamination Mechanism 


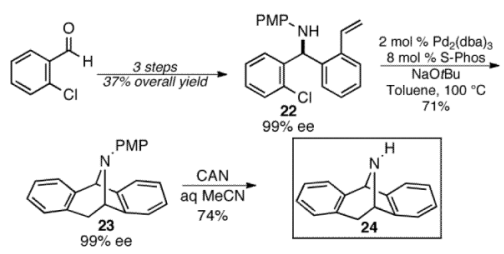

Scheme 4.

Pd-Catalyzed Synthesis of NMDA Antagonist 24 
Table 1

Optimization of Reaction Conditions ${ }^{a}$

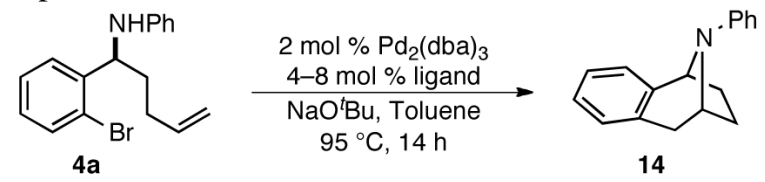

\begin{tabular}{cccc}
\hline entry & ligand & conversion $(\%)$ & yield of $\mathbf{1 4}(\%)^{\boldsymbol{b}}$ \\
\hline 1 & $\mathrm{P}(o-\text { tol })_{3}$ & 59 & 21 \\
2 & $\mathrm{P}\left(p-\mathrm{F}_{-} \mathrm{C}_{6} \mathrm{H}_{4}\right)_{3}$ & 100 & 69 \\
3 & DavePhos & 76 & 40 \\
$\mathbf{4}$ & $\mathbf{P C y}_{\mathbf{3}} \cdot \mathbf{H B F}_{\mathbf{4}}$ & $\mathbf{1 0 0}$ & $\mathbf{8 0}(\mathbf{7 7})^{c}$ \\
5 & dppf & 35 & 11
\end{tabular}

${ }^{a}$ Conditions: 1.0 equiv $4 \mathrm{aa}, 2.0$ equiv $\mathrm{NaO}^{t} \mathrm{Bu}, 2 \mathrm{~mol} \% \mathrm{Pd}_{2}(\mathrm{dba}) 3,8 \mathrm{~mol} \%$ ligand $(4 \mathrm{~mol} \%$ of dppf was used for the experiment shown in entry 5), toluene $(0.1 \mathrm{M}), 95^{\circ} \mathrm{C}, 14 \mathrm{~h}$.

${ }^{b}$ Yields were determined by ${ }^{1} \mathrm{H}$ NMR analysis of crude reaction mixtures that contained phenanthrene as an internal standard.

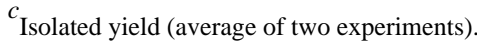


Table 2

Pd-Catalyzed Synthesis of Tropanes ${ }^{a}$

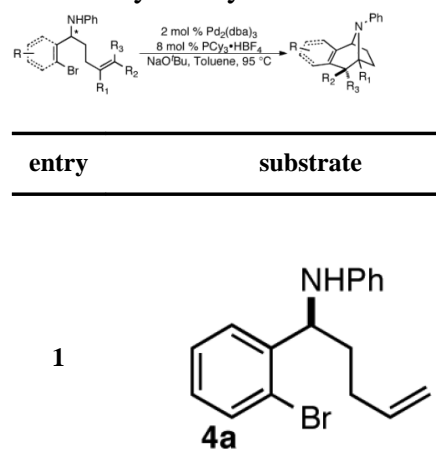

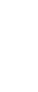

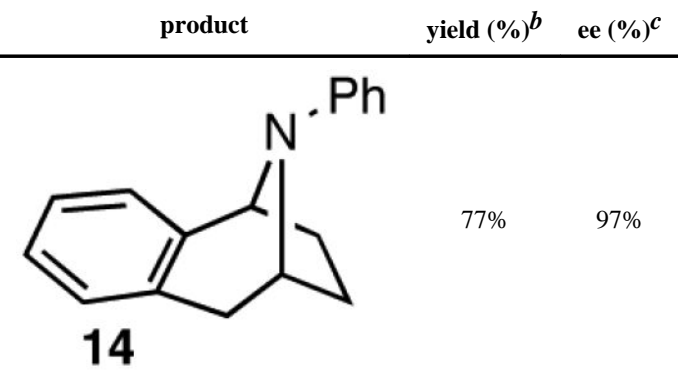

2<smiles>C=Cc1ccccc1[C@H](Nc1ccccc1)c1ccccc1Br</smiles><smiles>c1ccc(N2C3Cc4ccccc4C2c2ccccc23)cc1</smiles>

3<smiles>C=C(C)CCC(Nc1ccccc1)c1cc2c(cc1Br)OCO2</smiles><smiles>CC12CCC(c3cc4c(cc3C1)OCO4)N(c1ccccc1)C2</smiles>

4<smiles>C=CCC[C@H](Nc1ccccc1)c1ccncc1Br</smiles>

\section{4d}

5<smiles>C=CCCC(Nc1ccccc1)C1=C(Br)CCCC1</smiles>

$$
4 e
$$<smiles>C=C(C)CCC(Nc1ccccc1)C1=C(Br)CCC1</smiles>

6<smiles>c1ccc(N2C3CCC2c2ccncc2C3)cc1</smiles>

$81 \%$ $99 \%$

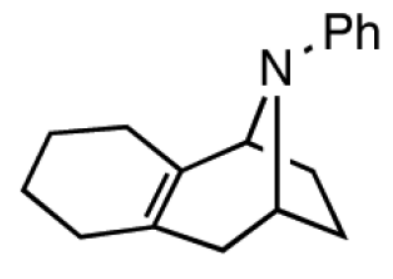

18

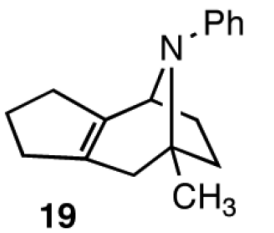




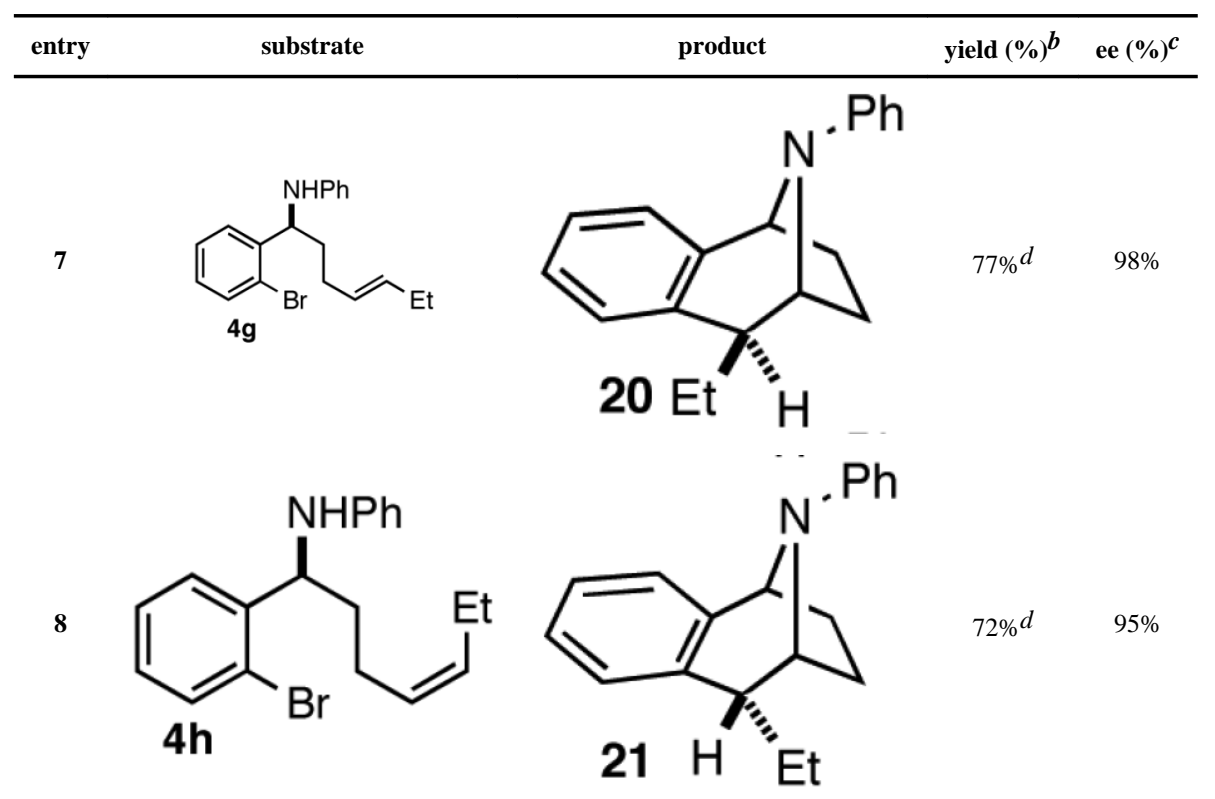

${ }^{a}$ Conditions: 1 equiv of amine, 1.5 equiv $\mathrm{NaO}^{t} \mathrm{Bu}, 2 \mathrm{~mol} \% \mathrm{Pd}_{2}(\mathrm{dba}) 3,8 \mathrm{~mol} \% \mathrm{PCy} 3 \cdot \mathrm{HBF}_{4}$, toluene $(0.1 \mathrm{M}), 95^{\circ} \mathrm{C}, 10 \mathrm{~h}$.

$b_{\text {Isolated yield (average of two experiments). }}$

${ }^{c}$ No racemization of the substrates occured during the transformation; the enantiopurities of the starting materials were within $1 \%$ ee of the tropane products as determined by chiral HPLC analysis.

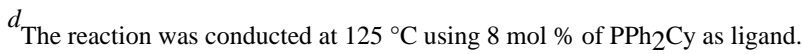

